Placenta. 2014 September ; 35(9): 780-783. doi:10.1016/j.placenta.2014.07.003.

\title{
Midregional pro-adrenomedullin plasma concentrations are blunted in severe preeclampsia
}

\author{
Brooke C. Matson ${ }^{1}$, Robert W. Corty ${ }^{2}$, Natalie O. Karpinich ${ }^{1}$, Amy P. Murtha ${ }^{3}$, William \\ Valdar $^{2}$, Chad A. Grotegut ${ }^{3}$, and Kathleen M. Caron ${ }^{1,2, \#}$ \\ Brooke C. Matson: brooke_matson@med.unc.edu; Robert W. Corty: robert_corty@med.unc.edu; Natalie O. Karpinich: \\ karpinic@email.unc.edu; Amy P. Murtha: murth002@mc.duke.edu; William Valdar: william.valdar@unc.edu; Chad A. \\ Grotegut: chad.grotegut@duke.edu \\ ${ }^{1}$ Departments of Cell Biology \& Physiology, University of North Carolina at Chapel Hill, North \\ Carolina, 27599, USA \\ 2Department of Genetics, University of North Carolina at Chapel Hill, North Carolina, 27599, USA \\ ${ }^{3}$ Division of Maternal-Fetal Medicine, Department of Obstetrics \& Gynecology, Duke University \\ School of Medicine, Durham, North Carolina, 27710, USA
}

\section{Abstract}

Levels of the peptide hormone adrenomedullin (AM) are elevated during normal pregnancy, but whether this differs during complications of pregnancy remains unresolved. AM can be quantified by measuring its preprohormone byproduct, midregional pro-adrenomedullin (MR-proADM).

MR-pro ADM has shown prognostic value as a biomarker of heart failure, sepsis, and communityacquired pneumonia. Given the relevance of AM to pregnancy, we tested the hypothesis that MRproADM provides a biomarker for preeclampsia. We find that MR-proADM plasma concentrations are blunted in severe preeclampsia and that MR-proADM is similarly effective as established biomarkers endoglin and placental growth factor at discriminating patients with severe preeclampsia from controls.

\section{Keywords}

adrenomedullin; midregional pro-adrenomedullin; preeclampsia; pregnancy

\section{Introduction}

Preeclampsia is a common pregnancy complication characterized by hypertension and proteinuria [1]. Identification of novel serum biomarkers for this potentially dangerous condition is highly desirable. The peptide hormone adrenomedullin (AM) has garnered

(C) 2014 Elsevier Ltd. All rights reserved.

${ }^{\#}$ Corresponding Author: Kathleen M. Caron, Department of Cell Biology \& Physiology, University of North Carolina at Chapel Hill, 111 Mason Farm Road, CB \#7545, 6312 MBRB, Chapel Hill, North Carolina, 27599, USA. Phone: (919) 966-5193 Fax: (919) 966-6927 kathleen_caron@med.unc.edu.

Publisher's Disclaimer: This is a PDF file of an unedited manuscript that has been accepted for publication. As a service to our customers we are providing this early version of the manuscript. The manuscript will undergo copyediting, typesetting, and review of the resulting proof before it is published in its final citable form. Please note that during the production process errors may be discovered which could affect the content, and all legal disclaimers that apply to the journal pertain. 
attention as a candidate biomarker of preeclampsia because its levels are elevated during pregnancy [2] but often altered in pregnancy complications [3]. Additionally, polymorphisms in the $A D M$ gene have been associated with preeclampsia [4].

Data from AM loss- and gain-of-function mouse models support a role for AM in placentation. Remodeling of uterine spiral arteries, conduits of the uteroplacental circulation, is critical for proper placentation [5] and is accomplished in part by crosstalk between uterine natural killer (uNK) cells and trophoblast cells of the placenta [6]. Compared to wild type placentas, $A d^{-/-}$placentas exhibit fewer uNK cells and insufficient spiral artery remodeling [7]. Placentas from an animal model of AM overexpression $\left(A d m^{h i / h i}\right)$ [8] concordantly exhibit more uNK cells than wild type placentas and upregulate expression of uNK cell-secreted signaling molecules [7]. $\mathrm{Adm}^{+/-}$intercrosses commonly produce embryos demonstrating fetal growth restriction and morphological abnormalities, both common consequences of placental disorders [9].

These data underscore the role of AM in placentation and its potential as a biomarker of preeclampsia. Previous studies arrived at inconsistent conclusions about changes in AM levels in preeclampsia [3], likely due to the brief half-life of AM [10] and its interaction with a binding protein [11]. Recently, an assay was developed to detect midregional proadrenomedullin (MR-proADM), a cleaved byproduct of the preprohormone that is in direct correlation with AM [12]. Here, we measured MR-proADM plasma concentrations in women with severe preeclampsia and compared this precursor peptide to previously established biomarkers of preeclampsia.

\section{Methods}

\section{Study design and patient samples}

The study was approved by the Institutional Review Boards of Duke University and the University of North Carolina at Chapel Hill. Thirty patients with preeclampsia and 30 patients without preeclampsia delivering at Duke University Hospital with available plasma samples were selected from the Pregnancy Outcomes: Blood and Tissue Repository study, which collected biological specimens from patients at the time of presentation and delivery. We subsequently limited our experimental group to women with severe preeclampsia by excluding women with mild preeclampsia $(\mathrm{n}=5)$. Additionally, women providing postpartum plasma samples $(n=12)$, women carrying twin pregnancies $(n=3)$, and smokers $(n=7)$ were excluded from the original cohort. Former smokers were considered nonsmokers.

\section{Immunoassays}

Endoglin and placental growth factor (PlGF) plasma concentrations were measured using commercial ELISA kits (R\&D Systems, Minneapolis, MN) (Supplementary Table 1). Plasma samples were diluted 1:5 for endoglin and 1:2 for PIGF. MR-proADM plasma concentrations were measured undiluted by Phadia Immunology Reference Laboratory (Portage, MI) using a commercial immunofluorescent assay (B.R.A.H·M.S KRYPTOR, Hennigsdorf, Germany) (Supplementary Table 1). 


\section{Statistics}

Student's t-tests were performed in GraphPad Prism 5.0. F tests were performed in R. Logistic regression and ROC analysis were performed using $\mathrm{R}$ package glm with no cross validation. $\mathrm{P}$ values $<0.05$ were considered statistically significant.

\section{Results}

Table 1 summarizes the clinical characteristics of the patients whose plasma was analyzed in this study (Figure 1A). Plasma samples from controls and from women with severe preeclampsia were analyzed by ELISA for conventional biomarkers of preeclampsia. As expected [13], soluble endoglin plasma concentrations were elevated in women with severe preeclampsia (Figure 1B), and placental growth factor (PIGF) plasma concentrations were blunted in women with severe preeclampsia (Figure 1C). After confirming that plasma from women with severe preeclampsia adhered to conventional biomarker paradigms, plasma samples were then analyzed by a sandwich immunoassay for MR-proADM. In women with severe preeclampsia, MR-proADM concentrations were blunted (Figure 1D). While plasma freezer storage time differed significantly between groups, storage time did not correlate with MR-proADM concentration $\left(\mathrm{r}^{2}=0.004\right.$, data not shown $)$.

To compare endoglin, PIGF, and MR-proADM as biomarkers of severe preeclampsia, we generated logistic regression models for each of these biomarkers alone and in combination. We then analyzed these models by generating receiver operating characteristic (ROC) curves and comparing their respective areas under the curve (AUC) (Figure 2). Based on AUCs, we concluded that, in this dataset, endoglin (AUC=0.73) and MR-proADM (AUC $=0.69$ ) classified patients similarly, while PIGF is slightly more informative (AUC=0.85). In multiple logistic regression, endoglin and MR-proADM together are better discriminators than either alone (AUC $=0.80$ ), as are PlGF and MR-proADM together (AUC=0.87).

\section{Discussion}

As predicted by the Adm-deficient mouse model [7, 9, 14], we found blunted MR-proADM plasma concentrations in women with severe preeclampsia. Interestingly, during our revision process, Wellmann et al. reported elevated MR-proADM in preeclampsia using a similarly sized cohort [15]. However, their study did not distinguish between mild and severe preeclampsia and included two key groups of patients that we excluded from our study: patients carrying multiple pregnancies and smokers. Both twins and smoking have been shown to upregulate $A d m$ expression, which could explain the finding of elevated AM plasma concentrations in their patients [16-18].

Moreover, we found that MR-proADM is similarly effective as endoglin and PIGF at discriminating between patients with severe preeclampsia and controls. However, as acknowledged as a methodology limitation in both studies, the disease prevalence is higher in the study population than in the general population. Additionally, both studies collected plasma samples late in pregnancy, while an ideal biomarker would detect preeclampsia early in pregnancy before the clinical disease becomes apparent. Ultimately, the data presented 
here warrant further investigation of MR-proADM at earlier gestational ages with the ultimate goal of predicting which women will develop preeclampsia later in pregnancy.

\section{Supplementary Material}

Refer to Web version on PubMed Central for supplementary material.

\section{Acknowledgments}

We thank Brian C. Antczak and Kristin W. Weaver for collection and processing of patient samples. This study was supported in part by the Department of Obstetrics and Gynecology at Duke University and by U.S. National Institutes of Health, grant \# HD060860 to K.M.C.

\section{References}

1. Steegers EA, von Dadelszen P, Duvekot JJ, Pijnenborg R. Pre-eclampsia. Lancet. 2010; 376(9741): 631-44. [PubMed: 20598363]

2. Gibbons C, Dackor R, Dunworth W, Fritz-Six K, Caron KM. Receptor activity-modifying proteins: RAMPing up adrenomedullin signaling. Mol Endocrinol. 2007; 21(4):783-96. [PubMed: 17053041]

3. Lenhart PM, Caron KM. Adrenomedullin and pregnancy: perspectives from animal models to humans. Trends Endocrinol Metab. 2012; 23(10):524-32. [PubMed: 22425034]

4. Lenhart PM, Nguyen T, Wise A, Caron KM, Herring AH, Stuebe AM. Adrenomedullin signaling pathway polymorphisms and adverse pregnancy outcomes. Am J Perinatol. 2014; 31(4):327-34. [PubMed: 23797962]

5. Pijnenborg R, Vercruysse L, Hanssens M. The uterine spiral arteries in human pregnancy: facts and controversies. Placenta. 2006; 27(9-10):939-58. [PubMed: 16490251]

6. Matson BC, Caron KM. Uterine natural killer cells as modulators of the maternal-fetal vasculature. Int J Dev Biol. Forthcoming.

7. Li M, Schwerbrock NM, Lenhart PM, Fritz-Six KL, Kadmiel M, Christine KS, Kraus DM, Espenschied ST, Willcockson HH, Mack CP, Caron KM. Fetal-derived adrenomedullin mediates the innate immune milieu of the placenta. J Clin Invest. 2013; 123(6):2408-20. [PubMed: 23635772]

8. Wetzel-Strong SE, Li M, Klein KR, Nishikimi T, Caron KM. Epicardial-derived adrenomedullin drives cardiac hyperplasia during embryogenesis. Dev Dyn. 2014; 243(2):243-56. [PubMed: 24123312]

9. Li M, Yee D, Magnuson TR, Smithies O, Caron KM. Reduced maternal expression of adrenomedullin disrupts fertility, placentation, and fetal growth in mice. J Clin Invest. 2006; 116(10):2653-62. [PubMed: 16981008]

10. Meeran K, O'Shea D, Upton PD, Small CJ, Ghatei MA, Byfield PH, Bloom SR. Circulating adrenomedullin does not regulate systemic blood pressure but increases plasma prolactin after intravenous infusion in humans: a pharmacokinetic study. J Clin Endocrinol Metab. 1997; 82(1): 95-100. [PubMed: 8989240]

11. Pio R, Martinez A, Unsworth EJ, Kowalak JA, Bengoechea JA, Zipfel PF, Elsasser TH, Cuttitta F. Complement factor $\mathrm{H}$ is a serum-binding protein for adrenomedullin, and the resulting complex modulates the bioactivities of both partners. J Biol Chem. 2001; 276(15):12292-300. [PubMed: 11116141]

12. Morgenthaler NG, Struck J, Alonso C, Bergmann A. Measurement of midregional proadrenomedullin in plasma with an immunoluminometric assay. Clin Chem. 2005; 51(10):18239. [PubMed: 16099941]

13. Levine RJ, Lam C, Qian C, Yu KF, Maynard SE, Sachs BP, Sibai BM, Epstein FH, Romero R, Thadhani R, Karumanchi SA. Soluble endoglin and other circulating antiangiogenic factors in preeclampsia. N Engl J Med. 2006; 355(10):992-1005. [PubMed: 16957146]

14. Li M, Wu Y, Caron KM. Haploinsufficiency for adrenomedullin reduces pinopodes and diminishes uterine receptivity in mice. Biol Reprod. 2008; 79(6):1169-75. [PubMed: 18716289] 
15. Wellmann S, Benzing J, Fleischlin S, Morgenthaler N, Fouzas S, Buhrer CA, Szinnai G, Burkhardt T, Lapaire O. Cardiovascular Biomarkers in Preeclampsia at Triage. Fetal Diagn Ther. 2014

16. Beiswenger TR, Feng L, Brown HL, Heine RP, Murtha AP, Grotegut CA. The effect of cigarette smoke extract on trophoblast cell viability and migration: the role of adrenomedullin. Reprod Sci. 2012; 19(5):526-33. [PubMed: 22267538]

17. Kraus DM, Feng L, Heine RP, Brown HL, Caron KM, Murtha AP, Grotegut CA. Cigarette smokeinduced placental adrenomedullin expression and trophoblast cell invasion. Reprod Sci. 2014; 21(1):63-71. [PubMed: 23653390]

18. Shinozaki H, Aoki H, Kasahara Y, Kangawa K, Minegishi T. Plasma adrenomedullin levels during multiple pregnancy. Gynecol Obstet Invest. 2010; 69(3):169-73. [PubMed: 20016189]

\section{Abbreviations}

$\begin{array}{ll}\text { ENG } & \text { endoglin } \\ \text { MR-proADM } & \text { midregional pro-adrenomedullin } \\ \text { PIGF } & \text { placental growth factor } \\ \text { ROC } & \text { receiver operating characteristic }\end{array}$




\section{Highlights}

- MR-proADM is a predictive and prognostic biomarker of heart failure and pneumonia.

- Animal models have defined a critical role for adrenomedullin in placentation.

- We conclude that MR-proADM is a novel plasma biomarker for severe preeclampsia.

- MR-proADM is similarly effective as endoglin at classifying patients from controls. 

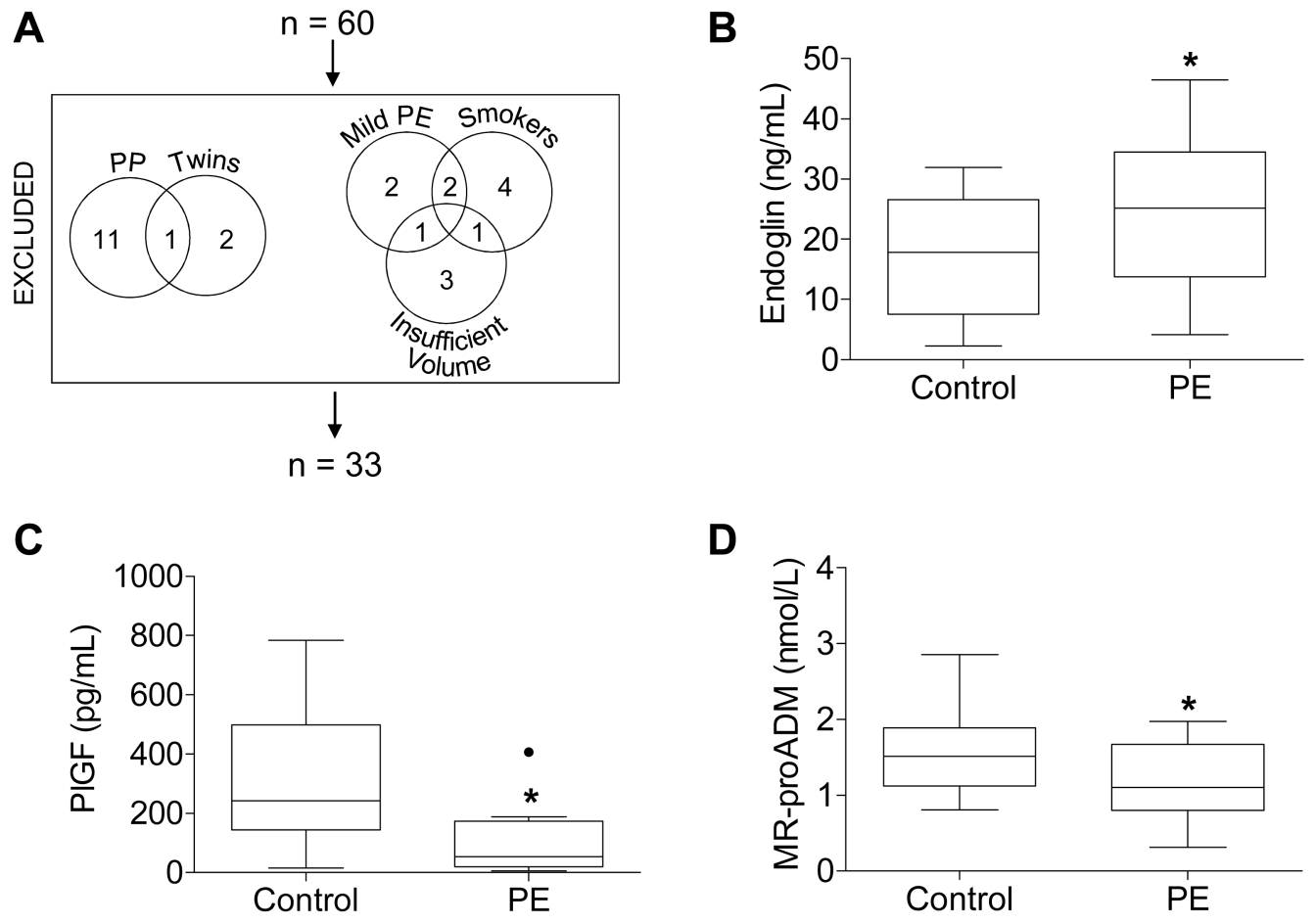

Figure 1.

(A) Patients excluded from the original 60 patient cohort and (B-D) plasma concentrations of (B) endoglin, (C) placental growth factor (PlGF), and (D) MR-proADM measured by ELISA (A, B) or sandwich immunoassay $(C)$ in controls and women with severe preeclampsia $(\mathrm{PE})$. Boxes extend from the $25^{\text {th }}$ to the $75^{\text {th }}$ percentile. Whiskers extend 1.5 times the interquartile range below and above the $25^{\text {th }}$ and $75^{\text {th }}$ percentiles, respectively. Horizontal lines dividing the boxes identify the median of each group. Significant outliers, determined by Grubbs' test, are identified by a solid black dot and excluded from the analysis in this figure. Four plasma samples were too concentrated to be detected within the range of the endoglin ELISA standard curve; one of these samples belonged to the control group, while the other three belonged to the PE group. Likewise, four plasma samples were too dilute to be detected within the range of the PIGF ELISA standard curve; all four of these samples belonged to the PE group. These too-concentrated or too-dilute samples were excluded from analysis. Groups were compared by Student's t-test. *p=0.046 (A) and 0.007 (B), and 0.041 (C). PP, postpartum. 


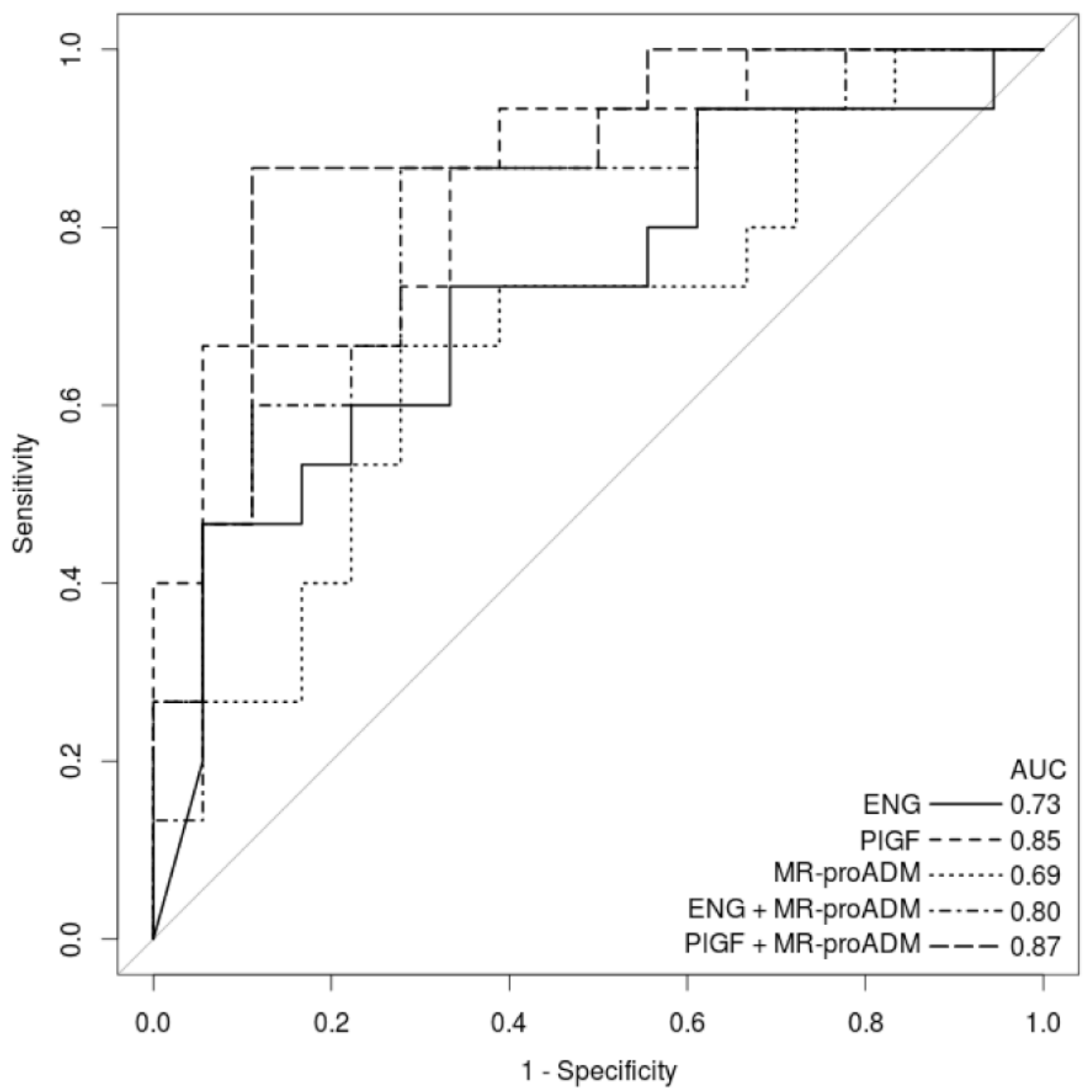

Figure 2.

ROC curves for five logistic regression models of current severe preeclampsia based on biomarker concentrations. Plus signs separate covariates. Samples that fell above (endoglin, $\mathrm{n}=4$ ) or below (PlGF, $\mathrm{n}=5$ ) the ELISA standard curve were equated with the upper and lower bounds, respectively, of the standard curve. ENG, endoglin. 


\section{Table 1}

Clinical characteristics of study patients.

\begin{tabular}{|c|c|c|c|}
\hline & Control (n=18) & Severe Preeclampsia $(n=15)$ & $p$ value $^{b}$ \\
\hline Age (years) & $33.8 \pm 4.5(25-41)$ & $28.5 \pm 6.6(21-41)$ & 0.01 \\
\hline BMI at delivery & $31.4 \pm 6.7(23.2-48.6)(n=17)$ & $38.2 \pm 9.2(25.6-54.0)$ & 0.03 \\
\hline Gravidity & $3(3-4)$ & $2(1-3)$ & 0.02 \\
\hline Parity & $1(1-2)$ & $0(0-2)$ & 0.14 \\
\hline \multicolumn{4}{|l|}{ Ethnicity } \\
\hline White & 12 & 7 & \\
\hline Black & 3 & 8 & 0.99 \\
\hline Asian & 3 & 0 & 0.07 \\
\hline Gestational age at delivery (weeks) & $38.7 \pm 0.8(37.2-39.7)$ & $33.9 \pm 4.2(27.4-39.9)$ & $<0.001$ \\
\hline \multicolumn{4}{|l|}{ Labor status } \\
\hline Not in labor & 14 & 10 & \\
\hline In labor & 4 & 5 & 0.48 \\
\hline \multicolumn{4}{|l|}{ Mode of delivery } \\
\hline Cesarean & 16 & 12 & \\
\hline Vaginal & 2 & 3 & 0.48 \\
\hline \multicolumn{4}{|l|}{ Blood pressure } \\
\hline Systolic $(\mathrm{mm} \mathrm{Hg})$ & $115.9 \pm 13.1(110-148)$ & $164.7 \pm 13.8(143-186)$ & $<0.001$ \\
\hline Diastolic (mm Hg) & $72.5 \pm 9.1(57-92)$ & $103.9 \pm 8.4(90-115)$ & $<0.001$ \\
\hline \multicolumn{4}{|l|}{ Proteinuria } \\
\hline Protein dip & $0.28 \pm 0.75(0-3)$ & $2.6 \pm 1.1(1-4)(n=10)$ & $<0.001$ \\
\hline \multicolumn{4}{|l|}{ Past medical history } \\
\hline Hypertension & 0 & 7 & \\
\hline \multicolumn{4}{|l|}{ Pregnancy-related morbidity } \\
\hline Gestational diabetes & 1 & 4 & 0.12 \\
\hline HELLP syndrome & 0 & 3 & \\
\hline Chorioamnionitis & 0 & 1 & \\
\hline Birthweight (grams) & $3488 \pm 393(2980-4710)$ & $2309 \pm 1191(590-4850)$ & $<0.001$ \\
\hline Fetal growth restriction & 0 & 3 & \\
\hline Freezer storage time (days) & $426.1 \pm 295.8(133-1024)$ & $837.2 \pm 322.0(155-1099)$ & $<0.001$ \\
\hline
\end{tabular}

Data are presented as mean \pm standard deviation (range). Gravidity and parity are presented as median (interquartile range). The $\mathrm{n}$ is provided if different from the group $\mathrm{n}$ due to unavailable data.

BMI, body mass index; HELLP, hemolysis, elevated liver enzymes, low platelets.

${ }^{a}$ Standard diagnostic criteria for severe preeclampsia were used: a systolic blood pressure $\geq 160 \mathrm{~mm} \mathrm{Hg}$ and/or a diastolic blood pressure $\geq 110 \mathrm{~mm}$ $\mathrm{Hg}$ and proteinuria $>500 \mathrm{mg} / 24$ hours.

${ }^{b}$ Student's t-test for continuous variables, $\mathrm{F}$ test for categorical variables. 
Table 2

Plasma concentrations of endoglin, PIGF, and MR-proADM in controls and women with severe preeclampsia.

\begin{tabular}{llll}
\hline & Control & PE & $\boldsymbol{p ~ v a l u e ~}^{\boldsymbol{a}}$ \\
\hline Endoglin $(\mathrm{ng} / \mathrm{mL})$ & $16.5 \pm 9.6(2.2-32.0)(\mathrm{n}=17)$ & $25.3 \pm 13.1(4.2-46.4)(\mathrm{n}=12)$ & 0.046 \\
PlGF $(\mathrm{pg} / \mathrm{mL})$ & $317.3 \pm 211.7(15.1-784.4)$ & $113.4 \pm 120.1(5.9-406.4)(\mathrm{n}=11)$ & 0.007 \\
MR-proADM (nmol/L) & $1.6 \pm 0.6(0.8-2.9)$ & $1.2 \pm 0.5(0.3-2.0)$ & 0.041 \\
\hline
\end{tabular}

Data are presented as mean \pm standard deviation (range). Plasma samples that were too concentrated or too dilute to be detected within the range of the ELISA standard curve for endoglin and PIGF, respectively, were excluded from analysis. Grubbs' test detected one significant outlier in the PIGF concentrations in the PE group; this outlier was also excluded from analysis.

${ }^{a}$ Student's t-test. 